\title{
Synthesis and Behavior of $\alpha$-Iminocarboxyamide Nickel and Zirconium Catalysts Towards Olefin Polymerization
}

\author{
Abdulhamid Ahmad Alsaygh \\ King Abdulaziz Military Academy, Riyadh, \\ P.O.BOX 58898, Riyadh, 11515, KSA \\ asaygh@yahoo.com
}

\begin{abstract}
Synthesis and investigations of Nickel-based olefin oligomerization and polymerization catalysts, $\alpha$-Iminocarboxyamide $\mu 3-P e n z y l ~ N i(I I)$ Complex(2) is reported. The attempt to improve the yield of the synthesis of the above mentioned catalysts by the direct reaction of the potassium salt of the ligand, $\mathrm{Ni}(\mathrm{COD})_{2}$ (bis(1,5cyclooctadiene)-nickel, and Benzyl halide in THF and starting temperature of $-35^{\circ} \mathrm{C}$. Led instead to disclose that the less hindered $\mathrm{N}$-aryal moieties on the diimine complexes the more difficult to synthesize the ethylene polymerization catalyst, Instead, yielding the di $\alpha$-Iminocarboxyamide Ni-complex(5) which is inactive towards ethylene polymerization. This promoted us to synthesize the complex di $\alpha$-Iminocarboxyamide $\mathrm{Zr}$-complex(6) which is activated by MAO for ethylene polymerization.
\end{abstract}

\section{Introduction}

Since the discovery of the new metalloccene-based type, Ziegler-Nata, catalysts $^{[1]}$, there has been an immense interest in the developments of new types of catalysts such as the utilization of the Nickel catalysts that are used for ethylene polymerization and oligomerization Shill Higher Olefin Process (SHOP) ${ }^{[2-4]}$. These types of catalysts have generated lots of research in the area of late transition metals catalysts with the emphasis on the influence of the legend structure on catalysts activity towards ethylene polymerization ${ }^{[5,6]}$. 
Brookhart and others have demonstrated that ( $\alpha$-diimine) Nickel dihalides complexes catalyze the polymerization of ethylene in the presence of an activating agent or co-catalyst: Methylaluminoxane $(\mathrm{MAO})^{[7,8]}$.

Bazan et al. have discovered that the reactivity of a new type of catalysts $\alpha$-Iminocarboxyamide $\mu 3$-Penzyl Ni(II) Complex, increases considerably upon addition of $\mathrm{B}\left(\mathrm{C}_{6} \mathrm{~F}_{5}\right)_{3}$. Carbonyl coordination to the borane removes electron density from nickel. This "activation" by action of a Lewis acid on a site removed from the monomer insertion trajectory prompted our attention ${ }^{[9]}$. The metal activation by formation of carbonyl adducts creats a new basis for designing novel nickel olefin polymerization and oligomerization catalysts. Compounds 1-3 were recently prepared in Bazans' labs and exemplify the group strategy. Resonance structures I and II illustrate the loss of electron density at nickel upon coordination to $\mathrm{B}\left(\mathrm{C}_{6} \mathrm{~F}_{5}\right)_{3}{ }^{[11]}$.

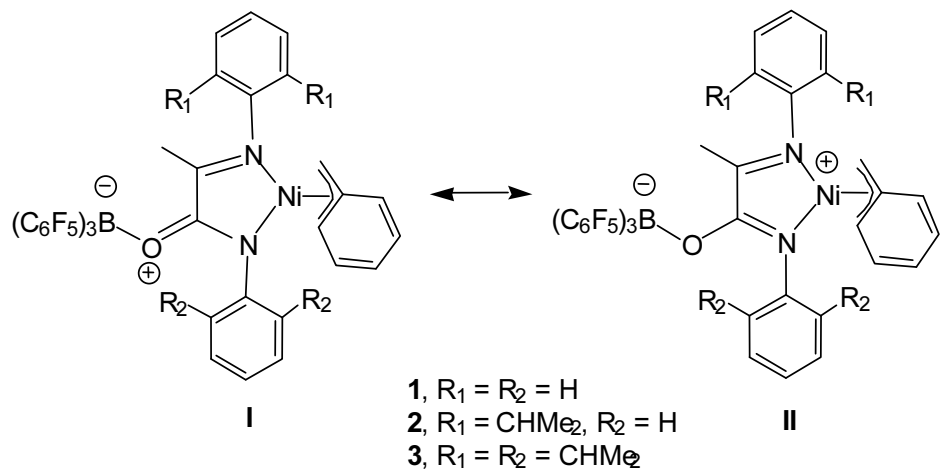

$\alpha$-Iminocarboxamide ligands were chosen because they can be readily prepared and because the size of the nitrogen aryl groups can be varied to modulate steric effects. Of interest to us was to control the size of the substituents on the pseudo axial sites, since blocking these sites in other nickel catalysts reduces chain transfer to monomer. Incorporation of the $\mu^{3}$-benzyl fragment was selected, instead of the more frequently used methallyl, because it displays faster rates of initiation ${ }^{[12-16]}$.

Bazan group were having a great success in synthesizing the precursors of compounds $\mathbf{2}$ and $\mathbf{3}$ as shown in Scheme 1. But the yields are very close to $1 \%$ for the direct synthesis of $\mathbf{2}$ that is for the reaction:

$$
\mathrm{ML}+\mathrm{Ni}(\mathrm{COD})_{2}+\mathrm{C}_{6} \mathrm{H}_{5} \mathrm{CH}_{2} \mathrm{X} \longrightarrow \text { Precursors of } 2 \text { and } 3
$$


Since the $\alpha$-Iminocarboxyamide $\mu 3$-Penzyl Ni(II) Complex is least stericly hindered, it promises to produce a high molecular weight polyethylene. Therefore; I investigated and tried to understand the best conditions for the reaction, which would help elucidating all these types of reactions and eventually, providing the industry with a very practical catalysts.

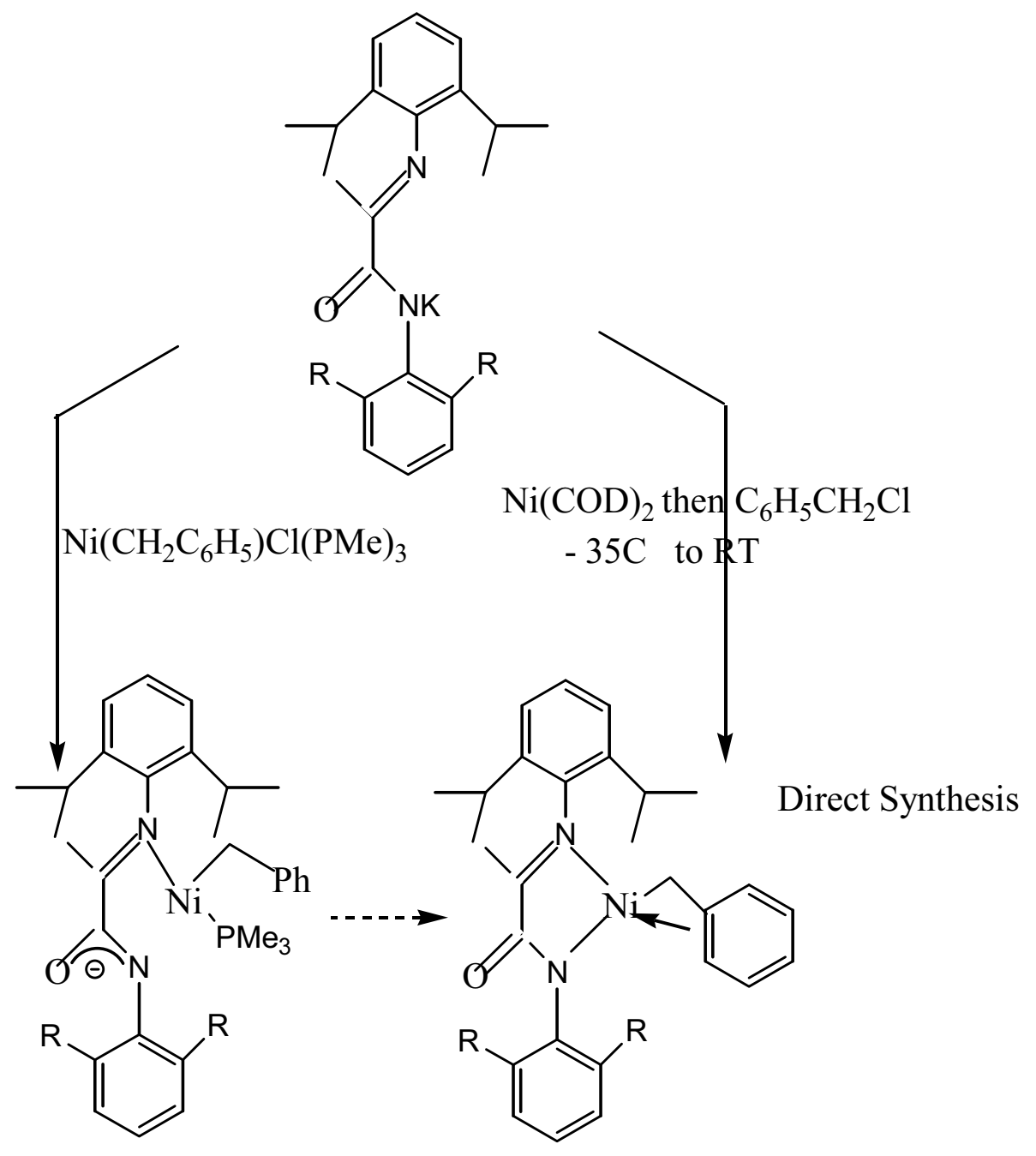

Scheme 1. Synthesis of $\alpha$-Iminocarboxyamide $\mu 3$-Penzyl Ni(II) Complex. 


\section{Experimental and Procedures}

All manipulations were performed under an inert atmosphere using standard glove box and Schlenk techniques. All reagents were used as received from Aldrich unless otherwise specified. Solvents like toluene, THF, hexane, and pentane were distilled from benzophenone ketyl. Purification of the catalysts were done by recrystallization via slow diffusion of Pentane at $-35^{\circ} \mathrm{C}$. NMR spectra were obtained using a Varian Unity 400 spectrometer. Elemental analysis was performed at physics department at UCSB.

Typical Schiff-base condensation of primary arylamines with $\mathrm{N}$-aryl pyruvamides yields $\alpha$-iminocarboxamides ${ }^{[5,6]}$. As shown in Scheme 1, carboxamide deprotonation with 1.0 equiv $\mathrm{KH}$, followed by reaction with $\mathrm{Ni}(\mathrm{COD})_{2}$ and benzyl chloride ${ }^{[13,14]}$.
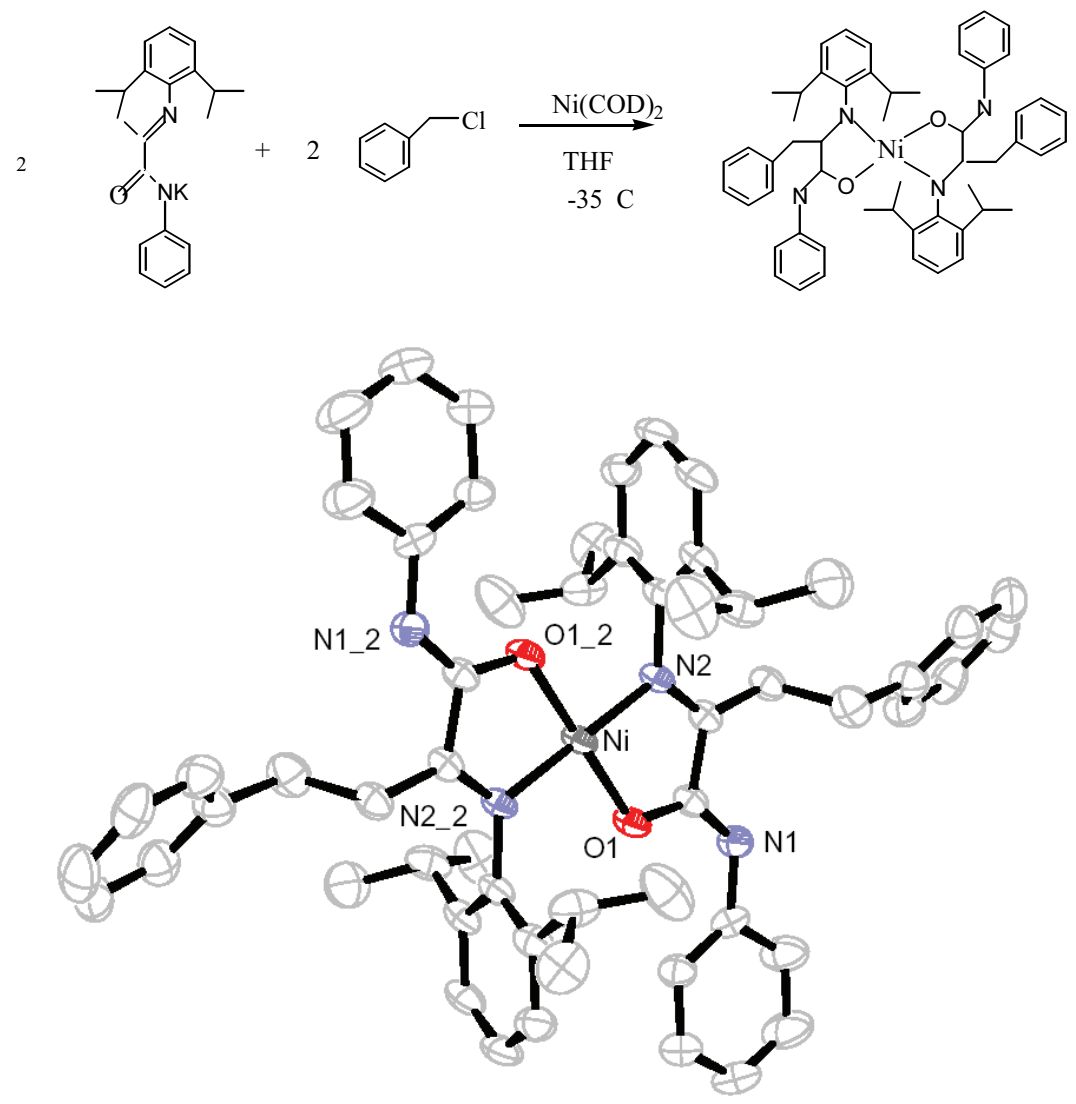

Fig. 1. X-ray structure of Nickel dimmer(4). 


\section{Synthesis of ( $\alpha$-iminocarboxamides) ${ }_{2}$ Ni complex, 5.}

$0.36 \mathrm{~g}(10 \mathrm{mmol})$ of the potassium salt of the ligand was placed in 50 $\mathrm{ml}$ vile with $26 \mathrm{ml}$ THF. To it, $0.33 \mathrm{~g}$ (10mmol) of $\mathrm{DMENiBr}_{2}$, was added and the reaction mixture was stirred for four hours, then, the resultant red brown was filtered through a fritted glass, the solvent was pulled off and the red brown solid purified by washing with pentan and recrystallization from toluene and characterized by ${ }^{1} \mathrm{H}$ NMR and Its' crystal structure was obtained as shown in Fig. 2.

\section{Synthesis of (a-iminocarboxamides) ${ }_{2} \mathrm{Zr}$ complex, 6.}

$0.36 \mathrm{~g}(10 \mathrm{mmol})$ of the potassium salt of the ligand was placed in 50 $\mathrm{ml}$ vile with $26 \mathrm{ml}$ THF. To it, $0.46 \mathrm{~g}(5 \mathrm{mmol})$ of $\mathrm{ZrCl}_{4}$, , was added and the reaction mixture was stirred for eight hours, then, the resultant yellow solution was filtered through a fritted glass, the solvent was pulled off and the yellow solid purified by washing with pentane and recrystallization from toluene characterized by ${ }^{1} \mathrm{H}$ NMR as shown in Fig. 3. Anal. : $\mathrm{C}_{42} \mathrm{H}_{50} \mathrm{~N}_{4} \mathrm{O}_{2} \mathrm{Cl}_{2} \mathrm{Zr}$, Theory: $\mathrm{C}, 60.8 \%$; H, 6.22\%; N, 6.96\%. Found: $\mathrm{C}, 60.75 ; \mathrm{H}, 6.13 ; \mathrm{N}, 6.48$.

\section{Results and Discussions}

As shown in Scheme 1, the direct rout of the synthesis is very delicate process; since $\mathrm{Ni}(\mathrm{COD})_{2}$ is very light sensitive, the reaction is done under dark condition to prevent it from decomposing before it reacts with the salt of the ligend. Moreover, the order of addition of reaction agents is very important, that is we established that after mixing $\mathrm{Ni}(\mathrm{COD})_{2}$ with ligand salt, the benzyl chloride is added drop wise at $35^{\circ} \mathrm{C}$ in $\mathrm{THF}$.

By varying the reaction conditions, solvents types (toluene or THF), Halides types (benzyl halides), and the salts(potassium or Sodium) of the ligand. Following the reaction product by ${ }^{1} \mathrm{H} \mathrm{NMR}$, we were able to detect traces of the product with a mixture of the dimmers and some other complex (complex 4) that is determined by X-ray structure as shown in Fig. 1. In this latter complex it appeared that the benzyl group activated the carbon of methyl group of the $\alpha$-iminocarboxamides ligand! This is thought of, as a side product of the direct method.

This led to substituting DME for $\mathrm{Ni}(\mathrm{COD})_{2}$, as follow: 


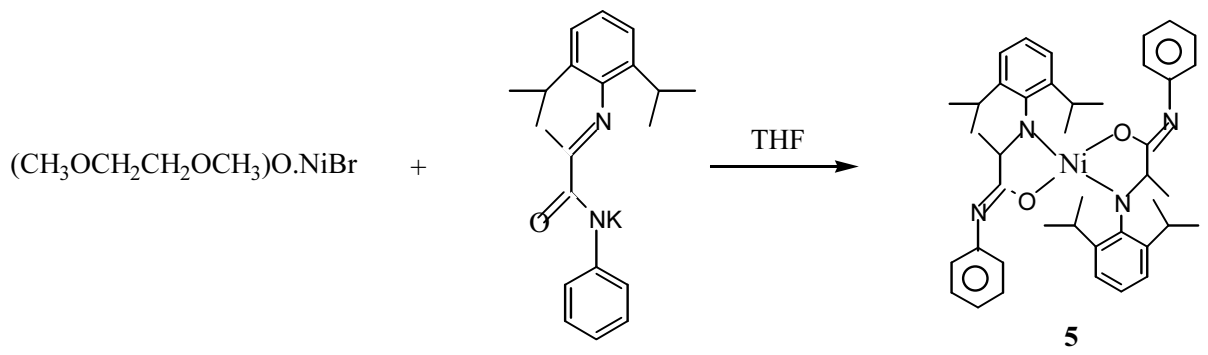

Scheme 2. Synthesis of ( $\alpha$-iminocarboxamides $)_{2} \mathrm{Ni}$ complex.

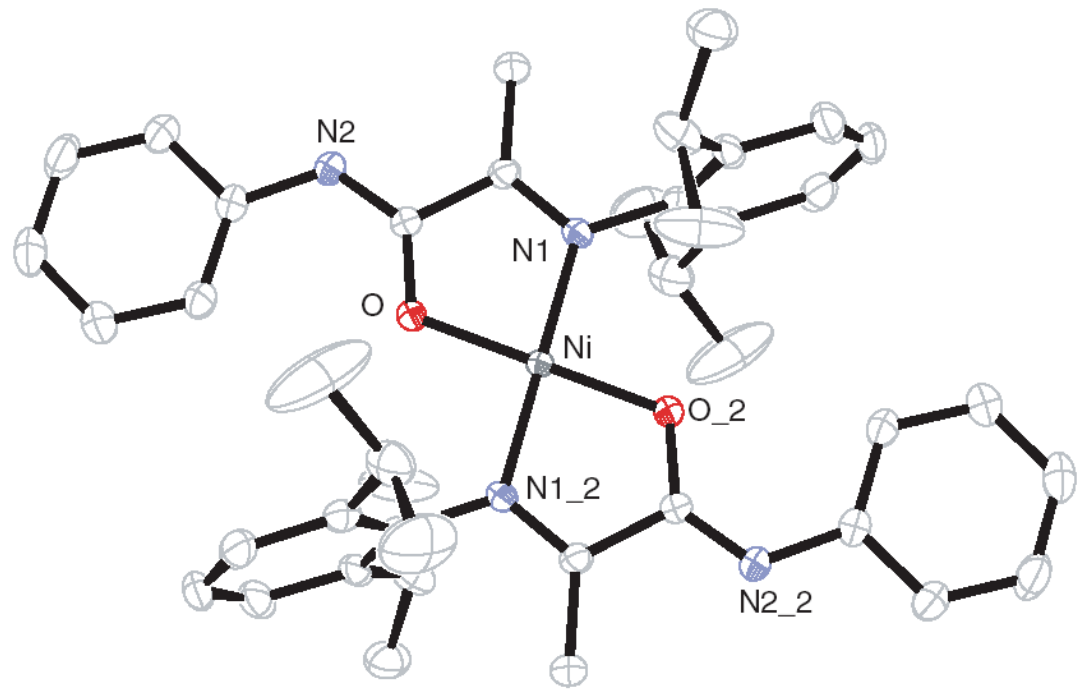

Fig. 2. X-ray structure of Nickel dimmer(5) the product of Scheme 2.

It became clear to us that the following reaction is attainable:

2<smiles>CC(C)c1cccc2c1N=C(C(=O)Nc1ccccc1)CC2C</smiles>

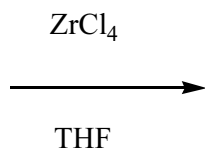

THF<smiles>CC(C)c1cccc(C(C)C)c1N(C)C(C)C(Nc1ccccc1)O[Te](Cl)(Cl)(Cl)C(Nc1ccccc1)C1CC(C)c2cccc(C(C)C)c2N1C(C)C</smiles>

6

Scheme 3. Synthesis of ( $\alpha$-iminocarboxamides $)_{2} \mathrm{Zr}$ complex. 
Complex 6 is obtained with a good yield and it was characterized by elemental analysis and ${ }^{1} \mathrm{H}$ NMR, see Fig. 3. It showed good activity towards ethylene polymerization if activated by MAO.

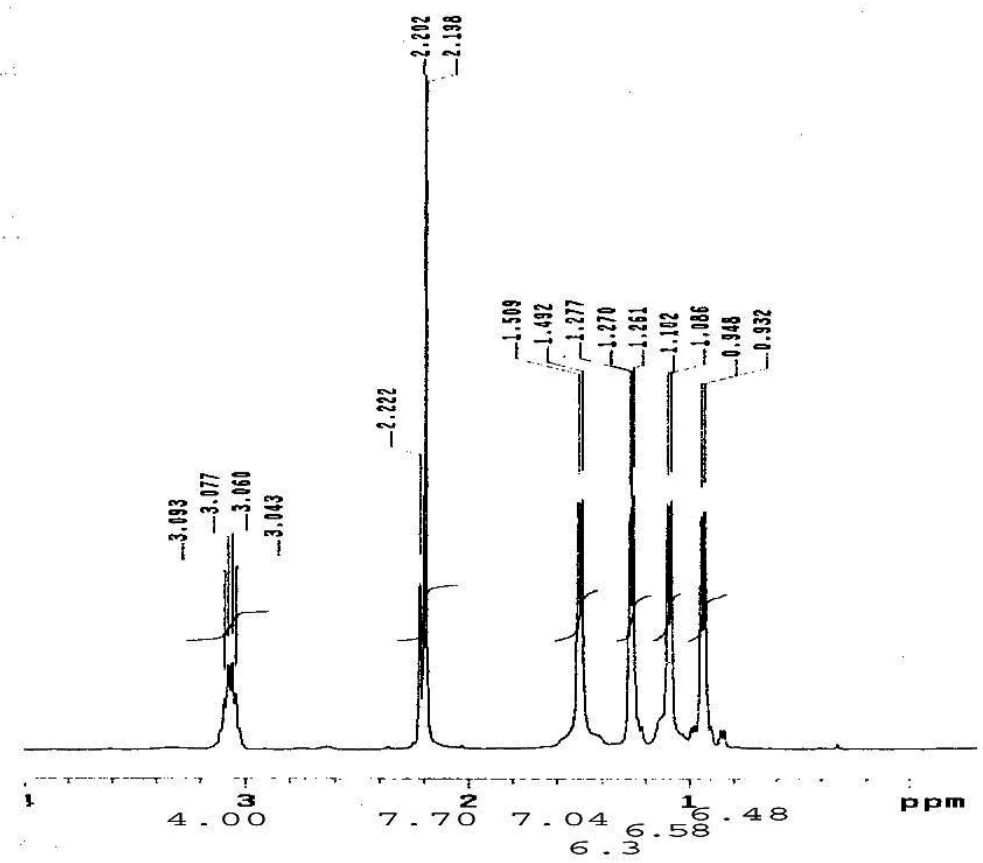

Fig. 3. ${ }^{1} \mathrm{H}$ NMR, in $\mathrm{C}_{6} \mathrm{D}_{6}$, of the aliphatic region of the Zirconium dimmer(6) from Scheme 3.

\section{Concluding Remarks}

The less sterically hindered Iminocarboxyamide, the more sensitive the catalyst synthesis to any minor changes in the procedure which opens up an opportunity for further research in this area ${ }^{[17]}$. The difficulties of synthesizing complex $\mathbf{2}$ by the direct method, Led to preparing new compounds 4, 5 and 6.

\section{Acknowledgments}

The authors deepest thanks and appreciations go for the US state department for the Fulbright scholarship. Prof. Guillermo C Bazan, Chemistry department at UCSB, for hosting me and enlightening me with fruitful research, and Dr. Guang Wu (X-ray lab manager,UCSB) for the crystal structure determinations. 


\section{References}

[1] Mecking, S., Coordination Chemistry Reviews, 203: 325-351 (2000).

[2] Park, S., Han, Y., Kim, S.K., Lee, J., Hwa Kyu Kim and Youngkyu Do., J. Organomet. Chem., 689: 4263-4276 (2004).

[3] Branquinho, R., A. C. Fernandes, Chien, J.C.W., Singh, R.P. and Marques, M.M., $J$. Organomet. Chem., 690: 1314-1323 (2005).

[4] Braunstein, P., J. Organomet. Chem., 689: 3953-3967 (2004).

[5] Tang, X., Sun, W.H., Gao, T., Hou, J., Chen, J. and Chen, W., J. Organomet. Chem., (2005) in press.

[6] Batten, M.P., Canty, A.J., Cavell, K.J., Ru"ther, T., Skelton, B.W. and White, A.H., Inoganica Chemica Acta (2005) Article in press.

[7] Peuckert, M. and Keim, W., Organometallics 2: 594 (1983).

[8] Small, B.L., Brookhart, M. and Bennett, A.M.A., J. Am. Chem. Soc., 120: 4049 (1998).

[9] Johnson, L.K., Killian, C.M. and Brookhart, M., J. Am. Chem. Soc., 117: 6414-6415 (1995).

[10] Killian, C.M., Tempel, D.J., Johnson, L.K. and Brookhart, M., J. Am. Chem. Soc., 118: 11664-11665 (1996).

[11] Komon, Z.J.A., Bu, X. and Bazan, G.C., J. Am. Chem Soc., 122: 1830-1831 (2000).

[12] Lee, B.Y., Bazan, G.C., Vela, J., Komon, Z.J.A. and Bu, X., J. Am. Chem. Soc., 123: 5352-5353 (2001).

[13] Kim, Y.H., Tae Ho Kim, Lee, B.Y., Woodmansee, D., Bu, X. and Bazan, G.C., Organometallics, 21: 3082-3084 (2002).

[14] Diamanti, S.J., Prasenjit Ghosh, Fumihiko Shimizu and Bazan, G.C., Macromolecules, 36 (2003) 9731-9735.

[15] Komon, Z.J.A., Diamond, G.M., Leclerc, M.K., Murphy, V., Okazaki, M. and Bazan, G.C., J. Am. Chem. Soc., 124: 15280-15285 (2002).

[16] Komon, Zachary, J.A., Bazan, G. C., Fang, C. and Xianhui, B., Inorganica Chemica Acta. 345(2003) 95-102.

[17] Rojas, R.S., Wasilke, J.C., Wu, G., Ziller, J.W. and Bazan, G C., Organometallics, 24: 5644-53 (2005). 


\title{
تحضير ودر اسة مركبات ألفا أمينوكربوكسيل أمبد لعنصر النيكل و الزركونيوم لاستخدامها كمحفز ات لبلمرة الإنلين
}

\author{
عبدالحميد أحمد الصايغ \\ كلبة الملك عبدالعزبز الحربية، \\ الرياض، المدلكة العربية السعودية \\ asaygh@yahoo.com
}

الستخظص. أجريت محاو لات تحضير دراسة مركبات النيكـلـ

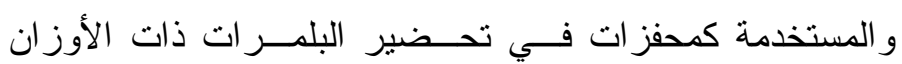

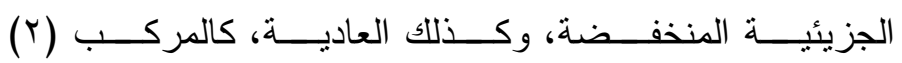
Iminocarboxyamide $\mu 3$-Penzyl Ni(II) لتحسين الناتج لتحضير هذا المركب عن طريق التفاعل المباشر

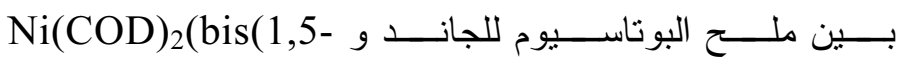
cyclooctadiene)-nickel

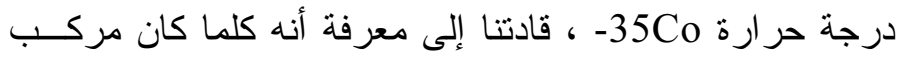

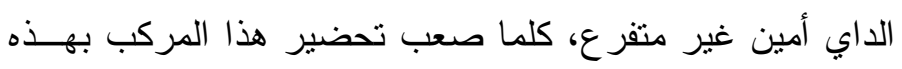

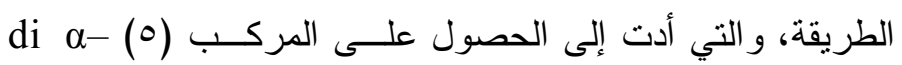
Iminocarboxyamide Nickel complex

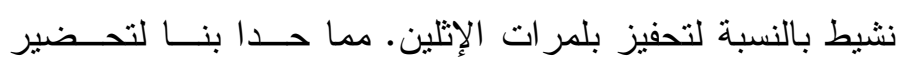

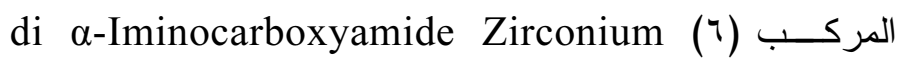
complex

$$
\text { وجود نسبة قليلة من مركب MAO. }
$$

